\title{
Deep Venous Thrombosis of Lower Limbs: Prevalence, Risk Factors and Treatment in Semi-Urban Areas in Senegal
}

\author{
S. J. Manga ${ }^{*}$, A. Ben Haj Younes ${ }^{1}$, M. Dioum², S. L. Sy², Q. Te Indafa1, M. B. C. Leye ${ }^{3}$ \\ ${ }^{1}$ Cardiology Department, Hospital de la Paix, Assane Seck University of Ziguinchor, Ziguinchor, Sénégal \\ ${ }^{2}$ Cardiologie Department, Fann National University Center, Dakar Cheikh Anta Diop University, Dakar, Sénégal \\ ${ }^{3}$ Cardiology Department, Regional Hospital of Mbour, Thiès University, Thiès, Sénégal \\ Email: *mangasimon@yahoo.fr
}

How to cite this paper: Manga, S.J., Younes, A.B.H., Dioum, M., Sy, S.L., Te Indafa, Q. and Leye, M.B.C. (2021) Deep Venous Thrombosis of Lower Limbs: Prevalence, Risk Factors and Treatment in Semi-Urban Areas in Senegal. Open Journal of Internal Medicine, 11, 194-200. https://doi.org/10.4236/ojim.2021.114015

Received: September 2, 2021

Accepted: October 30, 2021

Published: November 3, 2021

Copyright $\odot 2021$ by author(s) and Scientific Research Publishing Inc. This work is licensed under the Creative Commons Attribution International License (CC BY 4.0).

http://creativecommons.org/licenses/by/4.0/ (c) (i) Open Access

\begin{abstract}
Context and Objectives: Deep vein thrombosis (DVT) is a potentially serious affection because it can be complicated by life-threatening pulmonary embolism. Epidemiological data are scarce in Africa. The objective of this work was to describe the prevalence, risk factors and treatment of deep venous thrombosis (DVT) in Ziguinchor. Methodology: This was a retrospective study carried out at the Ziguinchor Peace Hospital from January 1, 2016 to June 30, 2020. We included in the study all patients of both sexes, aged at least 18 years and hospitalized with DVT of the lower limb confirmed by venous Doppler ultrasound. Results: A total of 64 patients were hospitalized for DVT of the lower limbs during the study, for a hospital prevalence of $3.9 \%$. The average age of the patients was 53 years $( \pm 17.6)$. A female predominance was noted with an M/F sex ratio of 0.7. The main risk factors found were the age $\geq 60$ years (36\%) and infectious pathologies (17\%). Clinical signs were dominated by lower limb pain (93.8\%) and lower limb edema (92\%). The lower limbs' venous Doppler ultrasound showed a predominance of thrombosis in the left lower limb (56\%). The femoral vein was the most affected in $90 \%$ of cases. The patients had all benefited from an anticoagulant treatment mainly by a low molecular weight heparin relayed from the 1st day by an antivitamin $\mathrm{K}$ that was acenocoumarol in $97 \%$ of the cases. The average length of hospitalization was 10 days. The complications found were pulmonary embolism (8\%) and accident with anticoagulants (3\%). Hospital mortality was $6 \%$. The average cost of care was 164.000 CFA francs. Conclusion: DVT is a multifactorial pathology; its treatment requires the control of risk factors. In our study, it was more frequent in the elderly.
\end{abstract}




\section{Keywords}

Deep Vein Thrombosis, Risk Factors, Pulmonary Embolism, Ziguinchor

\section{Introduction}

Deep venous thrombosis (DVT) is defined as the thrombotic obstruction of a deep venous trunk located most often in the lower limbs. It is considered to be one of the two entities of venous thromboembolic disease (VTE) with pulmonary embolism (PE) [1].

It represents a major public health problem in modern medicine, despite improvements in prophylaxis and advances in diagnostics. In fact, the incidence of DVT has not changed over the past decades. In young individuals, the incidence of DVT is 1 in 100,000, it is 1 in 1000 by the age of 40 and increases rapidly in the elderly, reaching in those over 85 years, 1 event per 100 person-years [2].

DVT is a serious disease causing significant morbidity and mortality. A recent Danish study demonstrated an overall mortality from DVT of $3 \%$ at 30 days and $13 \%$ at 1 year [3].

In Africa, epidemiological data on the lower limbs' DVT are scarce and difficult to collect. However, some studies carried out in hospitals give prevalence that varies between $1.1 \%$ and $4 \%$ [4] [5].

In Senegal, the hospital prevalence was $2.8 \%$ in the Cardiology Department of the Grand Yoff Hospital in Dakar [6].

Currently, no data on the prevalence of the lower limbs' DVT is available in Senegal outside of Dakar.

The objective of this work was to determine the prevalence, risk factors and DVT treatment at the Ziguinchor Peace Hospital.

\section{Methodology}

We carried out a retrospective study in the medical department of the Ziguinchor Peace Hospital from January 1, 2016 to June 30, 2020.

We included in the study all patients of both sexes, aged at least 18 years hospitalized with the lower limbs' DVT confirmed by venous Doppler ultrasound.

We did not include in the study all patients with suspicion of DVT not confirmed by ultrasound-venous Doppler and superficial venous thrombosis.

The data collection base consisted of the hospitalized for the lower limb's DVT patients records. The studied parameters concerned socio-demographic data (age, gender, socio-economic level, consultation time), personal and family history, hemodynamic constants, functional signs as well as clinical examination data. The additional examination results, the factors favoring the risk of developing DVT in our patients, the treatment and the hospital development were also studied.

These data were entered and analyzed using EPI-INFO version 7 software. 
The significance level was retained for a value of $\mathrm{p}<0.05$.

We made sure that the confidentiality of participants' study was ensured by using personal identification numbers on data collection forms instead of names. Personal identifiers will not be included in study reports. All study records are confidential.

\section{Results}

We had collected 64 cases of lower limb DVT during the study period. The prevalence was 3.9\%. The average age of the patients was $53 \pm 17.631$ years. Patients aged 60 and over represented $36 \%$ of the study population.

The female gender predominated with 38 women (59.4\%) for 26 men (40.6\%), i.e. a sex ratio $(\mathrm{M} / \mathrm{F})$ of 0.68 . The average consultation length was 10.06 days \pm 5.543 with extremes of 2 and 25 days.

The socio-demographic characteristics of the patients are summarized in Table 1.

Clinically, functional signs were dominated by pain in the lower limb (64\%) and the large leg (92\%).

The main general signs were tachycardia (64\%), increasing Mahler's pulse (42\%), fever (20\%) and polypnea (12.5\%).

Physical signs were dominated by loss of calf sloshing (93.8\%), lower limb edema (92.2\%) and Homans sign (84.4\%).

The clinical probability according to the Wells score was high in $56.2 \%$ of cases and intermediate in $43.8 \%$ of cases.

The ultrasound-venous Doppler of the lower limbs showed a predominance of thrombosis in the left lower limb in 56\% of cases against 35\% in the right. We noted $4 \%$ bilateral DVT.

Table 2 presents the main venous areas concerned: the femoral vein (25\%) and femoropopliteal lesions (23.4\%) were the most frequent.

Table 3 shows the different DVT risk factors of patients: age over 60 years (36\%), the presence of an infectious pathology (17.1\%) and Neoplasia (15.6\%).

For the DVT treatment, low molecular weight heparin has been used in all

Table 1. Socio-demographic characteristics of patients admitted for DVT.

\begin{tabular}{ccc}
\hline \multicolumn{1}{c}{ Variables } & & Frequence \\
\hline \multirow{2}{*}{ Sexe } & Man & $26(40.6 \%)$ \\
& Women & $38(59.4 \%)$ \\
Age & $<40$ years & $13(20.4 \%)$ \\
& $40-59$ years & $28(43.7 \%)$ \\
Résidence & $\geq 60$ years & $23(35.9 \%)$ \\
& Urban & $34(53.1 \%)$ \\
Socio-economical level & Rural & $30(46.9 \%)$ \\
& Good & $5(7.9 \%)$ \\
& Average & $17(26.5 \%)$ \\
& Low & $42(65.6 \%)$ \\
\hline
\end{tabular}


Table 2. Distribution of patients according to DVT territory.

\begin{tabular}{clcc}
\hline DVT scope & \multicolumn{1}{c}{ Venous territory } & Workforce & Percentage (\%) \\
\hline \multirow{3}{*}{ Limited DVT } & Femoral & 16 & 25 \\
& Popliteal & 3 & 4.68 \\
& Iliac & 1 & 1.56 \\
& Surale & 1 & 1.56 \\
& Femoro-popliteal & 15 & 23.4 \\
\multirow{2}{*}{ Extended DVT } & Surofemoro-popliteal & 14 & 21.8 \\
& Ilio-femoro-popliteal & 9 & 14 \\
& Ilio-femoral & 5 & 8 \\
\hline
\end{tabular}

DVT: deep venous thrombosis.

Table 3. Distribution of patients according to risk factors.

\begin{tabular}{|c|c|c|c|c|}
\hline \multicolumn{2}{|c|}{ Risk factors } & \multirow{2}{*}{$\begin{array}{c}\text { Workforce } \\
23\end{array}$} & \multirow{2}{*}{$\begin{array}{c}\text { Percentage (\%) } \\
36\end{array}$} & \multirow{2}{*}{$\begin{array}{c}\mathbf{P} \\
0.128\end{array}$} \\
\hline \multirow{6}{*}{ Medical risk factors } & Age $\geq 60$ ans & & & \\
\hline & Infectious athology & 11 & 17.1 & 0.333 \\
\hline & Neoplasia & 10 & 15.6 & 0.478 \\
\hline & IS & 4 & 6.2 & 0.647 \\
\hline & Heart disease & 4 & 6.2 & 0.647 \\
\hline & $\begin{array}{l}\text { Long trip with } \\
\text { prolonged sitting }\end{array}$ & 1 & 1.5 & 0.822 \\
\hline \multirow{4}{*}{$\begin{array}{l}\text { Gyneco-obstetric } \\
\text { risk factors } \\
\text { contraception }\end{array}$} & Contraception & 4 & 6.2 & 0.647 \\
\hline & Pregnancy & 3 & 4.6 & 0.550 \\
\hline & Cesarean & 2 & 3 & 0.767 \\
\hline & Postpartum & 1 & 1.6 & 0.822 \\
\hline $\begin{array}{l}\text { Recent surgical } \\
\text { and orthopedic }\end{array}$ & Digestive surgery & 2 & 3.1 & 0.767 \\
\hline risk factors & Plaster & 1 & 1.5 & 0.822 \\
\hline
\end{tabular}

IS: Ischemic Stroke.

patients. This was Enoxaparin sodium given at a dose of $0.1 \mathrm{IU} / 10 \mathrm{~kg}$ every 12 hours subcutaneously. Antivitamin K (AVK) was prescribed in all of our patients. They were used as an early relay to heparin from the 1st day of treatment. Acenocoumarol was the most commonly used AVK in $97 \%$ of cases. Two patients had been put on Fluindione. Direct oral anticoagulants (DOAs) were not prescribed in any of our patients. Analgesic treatment was prescribed in $66 \%$ of patients. Venous retention was used in 15 patients (23.4\%). The average hospitalization length was 10 days \pm 5 .

A favorable development under treatment was noted in 54 patients (85\%). In 5 patients (8\%) DVT was complicated by pulmonary embolism and two patients had an accident with overdose-type anticoagulants. We had four cases of death, a mortality of $6 \%$. We did not find any bad prognostic factors in our study. The 
average total cost of care was $164,414.06$ CFA francs $\pm 51,496.768$.

\section{Discussion}

DVT, once considered exceptional in black Africans, has seen an increase in its prevalence thanks to improved diagnostic methods. The prevalence of DVT, in our work, of $3.9 \%$ is comparable to that reported by several authors in Africa, south of the Sahara with a prevalence varying between $1.28 \%$ and $4 \%$ [5] [6] [7] [8]. The prevalence in hospitals seems lower in the West, varying between 0.6 and $0.9 \%$, certainly thanks to the reduction in postoperative DVT and good prophylaxis in patients at risk [9]. It seems necessary to carry out multicentric prospective studies to estimate the real prevalence of this pathology in our structures.

The predisposing factors to DVT found in our study are globally comparable to those reported in the literature except for thrombophilia, which has not been investigated due to the limitations of our medical platform. The old age is an important factor in the occurrence of DVT and the first episode of venous thrombosis' annual incidence increases almost exponentially with age, from about 0.28 per 1000 people between 20 to 39 years at 5 per 1000 after 75 years [10]. In our study, $36 \%$ of patients were over 60 years old and was the main risk factor found. Several authors found old age as the main predisposing factor to DVT in their study [4] [5] [6]. The physiological changes that occur in the elderly constitute, along with other risk factors, a favorable field for the DVT development. The increase in life expectancy in our regions and better control of infectious diseases could explain this trend. This should encourage us to take better preventive measures in the elderly at risk. Our study also made it possible to highlight the important place of infectious pathologies as predisposing factors to DVT in our region. These were mainly HIV infection and tuberculosis found in ten patients. Both tuberculosis and HIV infection can cause a state hypercoagulability responsible for thromboembolic events.

The clinical signs of DVT are nonspecific and not very sensitive. The clinical diagnosis is based on an examination, a complete clinical examination and the search for etiological risk factors.

The clinical signs found in our study are also comparable to those reported by most of the authors dominated by the painful large leg picture and edema. These clinical signs are not always specific, they are useful in evoking the diagnosis but do not by themselves allow to affirm or refute it from where currently the establishment of clinical prediction scores for a DVT clinical probability's appreciation [11]. The Wells clinical score, which we used in our study, found a high probability in $56 \%$ and could constitute, in our context where access to additional tests is limited, a means of rapid management by the initiation of anticoagulant therapy without waiting for diagnostic confirmation. The main examinations in the diagnostic process of DVT are the determination of D-dimers and ultrasound-venous Doppler. In our study, the D-dimer assay was not per- 
formed in any patient because it was unavailable and therefore constitutes a limit to the diagnosis of DVT in our context. Ultrasound-Venous Doppler is the gold standard for diagnosing DVT. Its sensitivity and specificity are $97 \%$ in the diagnosis of DVT in symptomatic patients [11]. The availability and accessibility of this diagnostic tool in our structures could greatly contribute to improving the diagnosis and management of DVT in our regions.

The treatment of DVT is mainly based on anticoagulation given in curative doses. The latest recommendations preferentially propose direct oral anticoagulants (DOA) because of the lower risk of bleeding. However, the cost and availability of AODs in our region constitute a barrier to their use. All of our patients had received a low molecular weight heparin at a curative dose relayed by AVK on the first day. This therapeutic attitude is reported in most African studies [6] [12].

Our work shows that pulmonary embolism remains the most serious complication of DVT. In our study, 5 patients (8\%) were complicated by pulmonary embolism with a mortality rate of $6 \%$ mainly by pulmonary embolism without significant correlation found however. Indeed, over 70\% of pulmonary embolism cases are secondary to lower limb DVT and around 50\% of patients with proximal DVT also have PE, which is most often asymptomatic [13].

The limits of this work are based on its retrospective nature and the limited size of our cohort.

\section{Conclusion}

DVT is a profound and frequent pathology especially in the elderly and its diagnosis is difficult in our context given the limits of our technical platform. The main complication in our study is pulmonary embolism that can be life threatening. The search for risk factors for DVT in all hospitalized patients could make it possible to reduce its incidence through adequate preventive measures as well as the availability of diagnostic means in our medical structures.

\section{Authors' Contribution}

All the authors contributed to the conduct of this work. All authors have read and approved the latest version of this manuscript.

\section{Conflicts of Interest}

The authors declare no conflict of interest.

\section{References}

[1] Richard, I. and Dominique, L. (2019) Thrombose veineuse profonde et embolie pulmonaire. Cardiologie, Paris, 307-333.

[2] Bénard, E., Lafuma, A. and Ravaud, P. (2005) Épidémiologie de la maladie thrombo-embolique veineuse. Presse Médicale, 34, 415-419.

https://doi.org/10.1016/S0755-4982(05)83934-X 
[3] Søgaard, K.K., Schmidt, M., Pedersen, L., Horváth-Puhó, E. and Sørensen, H.T. (2014) 30-Year Mortality after Venous Thrombœmbolism: A Population-Based Cohort Study. Circulation, 130, 829-836. https://doi.org/10.1161/CIRCULATIONAHA.114.009107

[4] Ben Salah, R., Frikha, F., Kaddour, N., Saidi, N., Snoussi, M. and Marzouk, S. (2014) Profil étiologique des thromboses veineuses profondes en milieu de médecine interne: Une étude rétrospective de 318 cas. Annales Cardiologie Angéiologie, 63, 11-16. https://doi.org/10.1016/j.ancard.2013.06.005

[5] Kake, A. and Sylla, D. (2017) Thrombose veineuse profonde des membres inférieurs: À propos de 40 cas colligés à Conakry [Deep Venous Thrombosis of the Lower Limbs in Conakry: A Series of 40 Cases]. Cardiologie Tropicale, 150, 1-5.

[6] Dioum, M. (2017) Les thromboses veineuses des membres: Aspects épidémiologiques, diagnostiques, thérapeutiques et évolutifs: Étude rétrospective sur une période de 09 ans à propos de 148 cas colliges au service de cardiologie de l'Hôpital Général de Grand Yoff de Dakar. Revue Africaine Malgache Recherche Sciences Santé, 5, 79-82.

[7] Ndiaye, E.M, Touré, N.O., Thiam, K., Cissé, M.F. and Dia, Y. (2015) Maladie thrombo-embolique veineuse: Aspect épidémiologique, clinique, paraclinique, étiologique et évolutif à la clinique de pneumologie du CHNU de Fann. Revue Maladies Respiratoires, 32, 176. https://doi.org/10.1016/j.rmr.2014.10.194

[8] Sangare, I., Ba, H.O., Fofana, C.A., Sidibe, N., Sogodogo, A.A. and Sanogo, K.M. (2015) Thrombophlebite des membres dans le service de cardiologie du CHU Gabriel Touré. Mali Médical, 30, 3-6.

[9] Allaert, F.A., Benzenine, E. and Quantin, C. (2017) Hospital Incidence and Annual Rates of Hospitalization for Venous Thrombœmbolic Disease in France and the USA. Phlebology Journal Venous Disease, 32, 443-447. https://doi.org/10.1177/0268355516653005

[10] Merminod, T. and De Mœrloose, P. (2002) Diagnostic de la thrombose veineuse profonde des membres inférieurs: Performances des tests diagnostiques. Annales Cardiologie Angéiologie, 51, 135-138. https://doi.org/10.1016/S0003-3928(02)00085-9

[11] Sabbah, L. (2015) Thrombose veineuse profonde et embolie pulmonaire. Cardiologie, Paris, 109-115. https://doi.org/10.1016/B978-2-294-74373-3.00019-X

[12] Ondze-Kafata, L.I., Kouala Landa, C., Traoré-Kissima, A., Loumouamou, M., Bani, M. and Amounya-Zobo, S. (2012) La thrombose veineuse des membres inférieurs à Brazzaville: À propos de 44 cas. Cardiologie Tropicale, 162, 11.

[13] Attias, D. and Lellouche, N. (2018) Cardiologie vasculaire. Vernazobres-Grego, Paris. 